\title{
RISK FACTORS FOR PERINATAL MORTALITY IN ARUA REGIONAL REFERRAL HOSPITAL, WEST NILE, UGANDA
}

\author{
Beatrice Akello ${ }^{1}$, Elizabeth Nabiwemba ${ }^{2}$, Christine Zirabamuzaale ${ }^{2}$ and Christopher Garimoi Orach ${ }^{2}$
}

Abstract

Background In low-income countries, the majority of neonatal deaths occur during the perinatal period. The fourth millennium development goal of reducing child mortality cannot therefore be met without substantial reduction in perinatal deaths.

Objective To investigate the risk factors for perinatal mortality in Arua regional referral hospital, West Nile region.

Methods We conducted a facility based unmatched case-control study at Arua Regional Referral hospital during January- March

2006. A total of 60 new cases of perinatal deaths and 120 controls were selected over a 3 months period. A case was defined as any baby born after 28 weeks of gestation either as a still birth or born alive but died within 7 days post delivery. A control was any baby born after 28 weeks of gestation and survived the first seven days of life. Control mothers were followed at home after one week to check if any perinatal death occurred. Logistic regression analysis was used to determine the risk factors for perinatal mortality.

Results: The mean age of case mothers was similar to that of controls 24.1 years, range 15-38 years versus 24.9 years range 16-40 years $(\mathrm{p}$-value $=0.52)$. Babies who died during the perinatal period were more likely not to have been resuscitated $(\mathrm{OR}=24.85,95 \%$ CI 8.77-74.17). Mothers whose babies died were more likely to have travelled more than 5 kilometres to Arua hospital $(\mathrm{OR}=3.89 \mathrm{CI}$ 1.96-7.74), having had transport problem $(\mathrm{OR}=3.35$, CI 1.00-12.00), first sought help from other health facilities or $T B A(O R=8.03$, CI 3.38-19.46), have been referred due to obstetric complications $(O R=11.45, C I$ 4.75-27.59), and had obstetric interventions i.e. C/S or vacuum extraction $(\mathrm{OR}=3.79$, CI 1.64-8.83). After controlling for confounding, significant risk factors for perinatal deaths included living more than 5 kilometres from the hospital (Adjusted OR= 0.91, CI 0.83-0.95), transport problem (Adjusted OR= 4.37, CI 1.14-39.75), baby not being resuscitated (Adjusted OR=4.87, CI 4.371-7.11) and baby being born with low Apgar score (Adjusted $O R=6.76$, CI 2.75-187.38).

Conclusion and Recommendations: Our study has identified several risk factors for perinatal deaths related to poor accessibility to and low quality of health care services in the setting. The study underscores the importance of improved accessibility to and quality of basic and comprehensive emergency obstetrical care. The findings suggest the need to improve the capacity of local health system at first, second and tertiary levels, accessibility to and quality health care services in the settings.

Key words: Perinatal mortality, risk factors, maternity care, West Nile, Uganda

\section{Introduction}

In low income countries, two thirds of neonatal deaths occur in the perinatal period. Although perinatal mortality (PNM) is preventable, globally an estimated 6.3 million babies die in the perinatal period annually. Almost all (98\%) of these deaths occur in developing countries (1-2). According to WHO, perinatal mortality rate stands at 62 per 1000 births in Africa, compared to an estimated rate of 10 per 1,000 births in the developed countries. $^{2}$ Perinatal mortality rate is estimated at 43 per 1000 births in Uganda (3).

In many developing countries of Africa and SouthWest Asia, the likelihood of a child dying in the first week of life is so great that infants are not counted until they are at least one week old, and stillbirths are not counted at all. Worldwide, a large proportion of infant deaths and disabilities originate in the perinatal period and are determined primarily by the condition of the pregnant mothers and the circumstances of the birth. ${ }^{\mathbf{1}}$ Information on perinatal mortality is limited in many African countries. Detailed analysis is made difficult by problems of isolation, poor communication, shortage of staff and incomplete record keeping including substantial under reporting especially in traditional societies. Weak routine information systems, inadequate vital registrations, and reliance on periodic household surveys

Correspondence: Christopher Garimoi Orach, Makerere University School of Public Health, Department of Community Health and Behavioural Sciences. P.O Box 7072, Kampala, Uganda. Tel: +256 77251 14 44; Fax: +256 41531807. Emails: cgorach@iph.ac.ug or cgorach@hotmail.com

${ }^{1}$ Mulago National Referral and Teaching Hospital, Kampala Uganda

Makerere University School of Public Health, Department of Community Health and Behavioural Sciences. as the main source of population-based data are all familiar obstacles to improving public health in poor countries. ${ }^{4}$ However, statistics on perinatal and neonatal mortality are useful in showing the magnitude of the problem and to suggest measures to ameliorate the problem.

During the 1980s, WHO promoted the risk approach which involved screening for risks and their classification during pregnancies based on maternal characteristics. The aim was to improve maternal and perinatal health particularly in developing countries. However, complications around the time of labour or delivery are not easily predictable. Several safe motherhood initiatives/interventions have been developed focusing on provision of effective care during labour. These include strengthening emergency obstetric services, having trained health workers with midwifery skills present at delivery, ensuring the availability of health facilities equipped with surgical capacity to provide essential major obstetric interventions coupled with the availability of effective referral systems.

In the West Nile region, Arua regional referral hospital serves a predominantly rural community estimated at 855,055 inhabitants. The district of Arua has a high growth rate of $3.98 \% .^{5}$ The population is predominantly peasantry with low socio-economic and health status. The human development and poverty indices in the northern region of Uganda including in the West Nile district of Arua are poor (6-8). The district health indices are poor with high under five mortality rate (U5MR) and infant mortality rate (IMR) of 240 and 100 per 1000 live births compared to the national figure of 152 and 88 respectively (9-10). This study aimed to investigate the risk factors for perinatal mortality, in the 
West Nile region in order to suggest measures towards reduction of perinatal deaths in the settings.

\section{Methods}

We carried out a hospital-based unmatched case control study to identify risk factors for perinatal deaths in Arua Regional Referral hospital, West Nile region. The hospital serves a predominantly rural community. The study was conducted over three months during JanuaryMarch 2006. The study population comprised mothers of babies born (alive or as stillbirths) in Arua hospital.

Data were collected from the hospital maternity ward. Mothers whose babies died from the hospital during the perinatal period between $1^{\text {st }}$ January $-31^{\text {st }}$ March 2006, were identified and recruited as case mothers into the study. A case was defined as any baby born after 28 weeks of gestation in Arua hospital either as a still birth, or who was born alive but died within one week post delivery. A control was defined as any baby born after 28 weeks of gestation in Arua hospital and survived the first seven days of life. The next two babies delivered after the case, born after 28 weeks of gestation but did not die within the first seven days of life were enrolled as controls. Two controls were selected per case. The babies whose mothers died during or immediately after delivery were excluded. Babies born before arrival in Arua Hospital or those born from other health centres but died in Arua hospital within one week of life were also excluded.

We collected data using a semi-structured questionnaire. The questionnaire was pre-tested in two hospitals in Arua District (Kuluva and Maracha). Interviewers were trained for 2 days prior to data collection.

The Zata were captured using EPINFO 2002 statistical package. SPSS software version 0.5 was used for multivariate analysis. Conditional logistic regression was performed to identify the predictors for perinatal mortality. All variables entered in the model were dichotomized, with PNM case as the outcome variable. The initial logistic regression model included all variables that were statistically significant during the bivariate analysis (e.g. distance to hospital, where first went for help, being referred, mode of delivery, Apgar score). Other variables that were not significant on bivariate analysis but that are known risk factors for perinatal death (e.g. order of pregnancy, maternal body mass index, antepartum haemorrhage, having sexually transmitted diseases, gross abnormality of baby) and potential confounders (e.g. maternal age) were also included in the model. Measures of interest were adjusted odds ratios (ORs) and confidence intervals (CIs) for perinatal mortality risk factors. Goodness of fit of the final model was tested by using Cox \& Snell $\mathrm{R}^{2}$ value.

\section{Results}

A total of 60 cases of perinatal deaths were identified from the maternity delivery record books. Two unmatched controls were selected for each of the 60 cases, giving a total of 120 controls.

The socio-demographic characteristics of case and control mothers were similar. The majority of babies who died and controls had mothers aged between 18-35 years. The mean age of case mothers of 24.1 years, range 15-38 years was similar to that of controls, 24.9 years range 1640 years $(p$-value $=0.5160)$. Most respondents were currently married, and had attained at least a primary education (Table 1). More than half $(58.3 \%)$ of the mothers whose babies died, and $66.7 \%$ of controls were over weight or obese. The vast majority $(95 \%)$ of the mothers whose babies died and $98.3 \%$ of control were not employed

The majority of mothers whose babies died $(90 \%)$ and $96.7 \%$ of controls lived within a distance of 5 kilometres from the nearest maternity centre. However, mothers of the babies who died were more likely to have lived more than five kilometres from Arua hospital (OR $=3.89$, 95\% CI 1.96-7.74) than controls.

Mothers of babies who died were more likely than control mothers to have first sought help from other health facilities/ or referred from TBAs. The majority of the mothers in both groups were referred due to labour complications. Mothers of babies who died were more likely to have had transport problems $(\mathrm{OR}=3.80, \mathrm{CI}$ 1.31-11.02) and obstetrical interventions like caesarean section and vacuum extraction than control mothers (OR $=3.79$, CI 1.64-8.83). The majority of case and control mothers had had spontaneous vaginal delivery (SVD) in the hospital. Having a doctor or midwife attending a SVD was protective against the occurrence of perinatal deaths $(\mathrm{OR}=0.18$, CI $0.016-2.05)$

On multivariate analysis, the best fitting model for factors associated with perinatal mortality explained $73.6 \%$ (Cox and Snell $\mathrm{R}^{2}$ ) of the variation observed in the outcome variable. Within this model, living within five kilometres from Arua hospital was significantly protective $(\mathrm{p}<0.0001)$ (Table 4). Booking for ANC at gestational age above 28 weeks, performing obstetrical interventions like $\mathrm{C} / \mathrm{S}$ and vacuum extractions $(\mathrm{V} / \mathrm{E})$ were not protective and were excluded from the final model. Delay in reaching the hospital due to transport problem, baby not being resuscitated and having low Apgar score of $\leq 6$ were associated with increased risks of perinatal death. 
Table 1: Socio-demographic background of mothers (Cases and Controls)

\begin{tabular}{|c|c|c|c|c|c|c|}
\hline \multirow[t]{2}{*}{ Characteristics } & \multicolumn{2}{|l|}{ Cases } & \multicolumn{2}{|c|}{ Controls } & \multirow[t]{2}{*}{ OR } & \multirow[t]{2}{*}{$95 \%$ CI } \\
\hline & $\mathrm{N}=60$ & $\%$ & $\mathrm{~N}=\mathbf{1 2 0}$ & $\%$ & & \\
\hline \multicolumn{7}{|l|}{ Age (years) } \\
\hline$<18$ and $>35$ & 7 & 11.7 & 16 & 13.3 & 0.86 & $0.30-2.40$ \\
\hline $18-35$ & 53 & 88.3 & 104 & 86.7 & 1.00 & \\
\hline \multicolumn{7}{|l|}{ Body mass index* } \\
\hline Over weight/obesity & 35 & 58.3 & 80 & 66.7 & 0.35 & $0.35-1.37$ \\
\hline Normal & 25 & 41.7 & 40 & 33.3 & 1.00 & \\
\hline \multicolumn{7}{|l|}{ Education level } \\
\hline None/primary & 57 & 95 & 115 & 95.8 & 0.83 & $0.16-4.54$ \\
\hline Secondary & 3 & 5 & 5 & 4.2 & 1.00 & \\
\hline \multicolumn{7}{|l|}{ Occupation } \\
\hline House wife/none/student & 57 & 95 & 118 & 98.3 & 0.32 & $0.04-2.45$ \\
\hline$* *$ Other & 3 & 5 & 2 & 1.7 & 1.00 & \\
\hline
\end{tabular}

Table 2: Access to health (facility) care

\begin{tabular}{|c|c|c|c|c|c|c|}
\hline \multirow[t]{2}{*}{ Characteristic } & \multicolumn{2}{|l|}{ Cases } & \multicolumn{2}{|l|}{ Controls } & \multirow[t]{2}{*}{ OR } & \multirow[t]{2}{*}{$95 \% \mathrm{CI}$} \\
\hline & $\mathbf{N}=\mathbf{6 0}$ & $\%$ & $\mathrm{~N}=120$ & $\%$ & & \\
\hline \multicolumn{7}{|l|}{$\begin{array}{l}\text { Distance to nearest maternity centre } \\
(\mathrm{km})\end{array}$} \\
\hline $6-20$ & 6 & 10 & 4 & 3.3 & 0.31 & $0.07-1.31$ \\
\hline $0-5$ & 54 & 90 & 116 & 96.7 & & \\
\hline \multicolumn{7}{|l|}{ Distance to Arua hospital (km) } \\
\hline $6-90$ & 28 & 46.7 & 22 & 18.3 & 3.89 & $1.96-7.74 *$ \\
\hline $0-5$ & 32 & 53.3 & 98 & 81.7 & & \\
\hline \multicolumn{7}{|l|}{$\begin{array}{l}\text { Place where help was first sought } \\
\text { (labour) }\end{array}$} \\
\hline $\mathrm{H} / \mathrm{C}+\mathrm{TBA}+$ other hospital & 27 & 45 & 12 & 9.2 & 8.03 & $3.38-19.46^{*}$ \\
\hline ARRH & 33 & 55 & 108 & 90.8 & 1.00 & \\
\hline \multicolumn{7}{|l|}{ Referred to Arua hospital } \\
\hline Yes & 27 & 45 & 8 & 6.7 & 11.45 & $4.75-27.59 *$ \\
\hline No & 33 & 55 & 112 & 93.3 & 1.00 & \\
\hline \multicolumn{7}{|l|}{ Reason for referral } \\
\hline Labour complication & 19 & 70.4 & 8 & 100 & 0.00 & $0.00-2.08$ \\
\hline Not labour complication & 8 & 29.6 & 0 & 0 & 1.00 & \\
\hline \multicolumn{7}{|l|}{ Had transport problems } \\
\hline Yes & 9 & 15.3 & 6 & 5 & 4.08 & $1.17-14.77^{*}$ \\
\hline No & 51 & 84.7 & 114 & 95 & 1.00 & \\
\hline \multicolumn{7}{|l|}{ Onset of Intervention in hospital } \\
\hline Delayed $\Phi$ & 2 & 3.3 & 7 & 5.9 & 0.55 & $0.08-3.03$ \\
\hline Immediate & 58 & 96.7 & 112 & 94.1 & 1.00 & \\
\hline \multicolumn{7}{|l|}{ Mode of delivery } \\
\hline $\mathrm{C} / \mathrm{S}$ and vacuum extraction & 20 & 33.3 & 14 & 11.7 & 3.79 & $1.64-8.83^{*}$ \\
\hline SVD & 40 & 66.7 & 106 & 88.3 & 1.00 & \\
\hline
\end{tabular}

Keys: $\mathrm{HC}=$ health centre; $\mathrm{C} / \mathrm{S}=$ caesarean section; TBAs $=$ traditional birth attendants; $\mathrm{SVD}=$ spontaneous vaginal delivery

I The 95\% confidence limits were calculated based on fisher's exact test 
Table 3: Maternal and Foetal conditions at birth

\begin{tabular}{|c|c|c|c|c|c|c|}
\hline \multirow[t]{2}{*}{ Condition } & \multicolumn{2}{|l|}{ Cases } & \multicolumn{2}{|c|}{ Controls } & \multirow[t]{2}{*}{ OR } & \multirow[t]{2}{*}{$95 \% \mathrm{CI}$} \\
\hline & $N=60$ & $\%$ & $N=120$ & $\%$ & & \\
\hline \multicolumn{7}{|l|}{ Maternal } \\
\hline \multicolumn{7}{|l|}{ Hypertension } \\
\hline Yes & 2 & 3.3 & 4 & 3.3 & 1.00 & $0.18-5.62$ \\
\hline No & 58 & 96.7 & 116 & 96.7 & 1.00 & \\
\hline \multicolumn{7}{|l|}{ Haemorrhage (APH) } \\
\hline Yes & 8 & 13.3 & 1 & 0.8 & 18.31 & $2.23-150.15^{*}$ \\
\hline No & 52 & 86.7 & 119 & 99.2 & 1.00 & \\
\hline \multicolumn{7}{|l|}{ Anaemia } \\
\hline Yes & 1 & 1.7 & 1 & 0.8 & 2.017 & $0.12-32.81$ \\
\hline No & 59 & 98.3 & 119 & 99.2 & 1.00 & \\
\hline \multicolumn{7}{|l|}{ Foetal } \\
\hline \multicolumn{7}{|l|}{ Cried immediately } \\
\hline No & 54 & 90 & 6 & 5 & 171.00 & $46.91-689.36^{*}$ \\
\hline Yes & 6 & 10 & 114 & 95 & 1.00 & \\
\hline \multicolumn{7}{|l|}{ Apgar score at 1 minute } \\
\hline $0-6$ & 54 & 90.0 & 2 & 1.7 & 531.00 & $91.29-4163.67^{*}$ \\
\hline $7-10$ & 6 & 10.0 & 118 & 98.3 & 1.00 & \\
\hline \multicolumn{7}{|c|}{ Apgar score at 5 minutes } \\
\hline $0-6$ & 55 & 91.7 & 0 & 0 & 0.00 & Not applicable \\
\hline $7-10$ & 5 & 8.3 & 120 & 100 & 1.00 & \\
\hline \multicolumn{7}{|l|}{ Baby resuscitated } \\
\hline No & 34 & 56.7 & 6 & 5 & 24.85 & $8.77-74.17 *$ \\
\hline Yes & 26 & 43.3 & 114 & 95 & 1.00 & \\
\hline \multicolumn{7}{|l|}{ Baby's birth weight } \\
\hline$<1500$ and $>3500 \mathrm{gm}$ & 10 & 16.7 & 20 & 16.7 & 1.00 & $0.435-2.297$ \\
\hline $1500-3500 \mathrm{gm}$ & 50 & 83.3 & 100 & 83.3 & 1.00 & \\
\hline
\end{tabular}

APH=Ante-partum haemorrhage

I The $95 \%$ confidence limits were calculated based on fisher's exact test

Mothers whose babies died were 18 times more likely to have had ante partum haemorrhage than control mothers $(\mathrm{OR}=$ $18.31,95 \%$ CI 2.23-150.14). Babies who had Apgar score of 7 and above (OR $=531.00$, CI 91.29-4163) were less likely to have died than controls (Table 3 ).

Figure: $\quad$ Delivery mortality outcomes

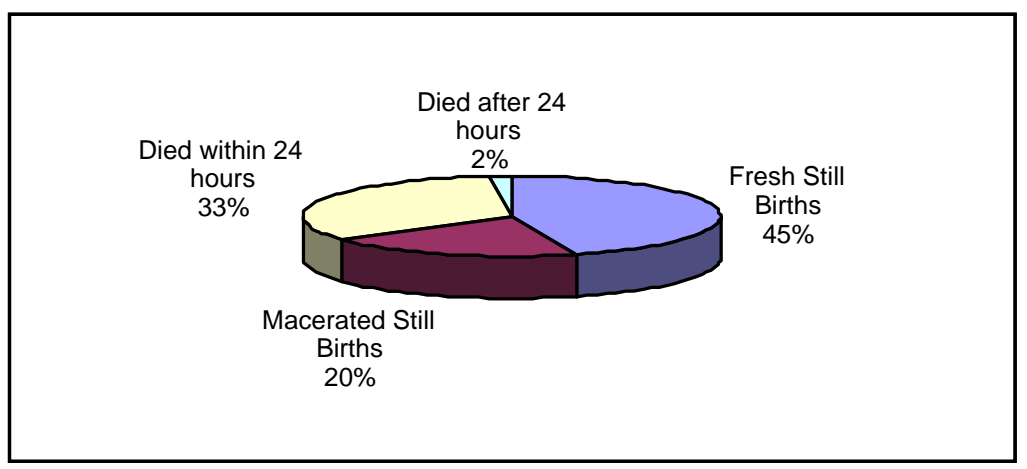

Nearly half of the babies 27 (45\%) were fresh stillbirths while 12 (20\%) were macerated stillbirths. Twenty (33.3\%) out of the babies who were born alive died within 24 hours as illustrated in the figure above. 
Table 4: Logistic model for risk factors associated with perinatal mortality

\begin{tabular}{|c|c|c|c|c|}
\hline Variable & Coefficient & $\begin{array}{l}\text { Adjusted } \\
\text { OR }\end{array}$ & $95 \% \mathrm{CI}$ & P-value \\
\hline Distance more than $5 \mathrm{~km}$ & -0.119 & 0.91 & $0.83-0.95$ & $0.000^{*}$ \\
\hline Distance to ARRH $5 \mathrm{~km}$ and below & & 1.00 & & \\
\hline Gestational age at booking above 28 weeks & -0.097 & 0.96 & $0.81-1.01$ & 0.086 \\
\hline Gestational age at booking below 28 wks & & 1.00 & & \\
\hline Taking long to reach ARRH when in labour & 1.907 & 4.43 & $1.14-39.75$ & $0.035^{*}$ \\
\hline Not taking long to reach Arua hospital & & 1.00 & & \\
\hline Birth weight below $1500 \mathrm{~g}$ and $>3500 \mathrm{~g}$ & 0.002 & 0.97 & $0.001-7.60$ & 0.041 \\
\hline Birth weight $1500 \mathrm{~g}$ to $3500 \mathrm{~g}$ & & 1.00 & & \\
\hline Baby not resuscitated & -17.162 & 4.87 & $4.37-7.11$ & $0.000 *$ \\
\hline Baby resuscitated & & 1.00 & & \\
\hline Apgar score $0-6$ & 3.122 & 6.76 & $2.75-187.38$ & $0.004 *$ \\
\hline Apgar score 7-10 & & 1.00 & & \\
\hline Normal delivery & -3.642 & 2.11 & $0.92-7.01$ & 0.062 \\
\hline Caesarean section + Vacuum extraction & & 1.00 & & \\
\hline
\end{tabular}

Key: ARRH $=$ Arua Regional Referral Hospital

\section{Discussion}

Our study has highlighted several risk factors for perinatal deaths in Arua regional referral hospital - WestNile setting, Uganda. The main factors identified relate to poor geographical and temporal accessibility to and low quality of health services evidenced by the lack of resuscitation of babies in the hospital, as well as low Apgar score of the newborn babies. Our findings are consistent with those of previous studies that identified universal access to basic health services before, during and after child birth as being protective against the occurrence of perinatal deaths (11). It is generally recognised that maternal health services are dependant on the functioning of the entire health system. Health systems factors influence the accessibility to and utilisation of services, quality of care provided and ultimately maternal (12) and child health outcomes.

In the West Nile region, health services delivery and health status are poor. Several factors including inadequate resources - financial, human, physical infrastructure, low socio-economic status and the remote geographical location of the district, influence the health and social services delivery in the region. Previous studies by other researchers (13-14) have also identified poor temporal and financial accessibility to health services for major obstetric interventions in the region. In the region (Arua district), both public and private means of transportation are scarce. The local health care system - local government lacks ambulance services. Thus, emergency transportation/referrals to a health facility for basic and comprehensive emergency health (obstetric) care remain a major challenge. This suggests an urgent need for the district local government (stakeholders) to improve emergency referrals systems including through acquisition of ambulance motor vehicle, as well as bicycle ambulances in every villages/parishes. There is also need to set up effective communication systems radio call systems to link up the peripheral health systems with the referral hospitals, both public and private facilities. In addition there is need to improve staffing in the rural-remote parts of the districts in the West Nile region. Trained personnel/human resources should be recruited, and satisfactorily remunerated and motivated to work in such remote settings. Furthermore, the health facilities need to be adequately equipped with essential equipment, drugs and supplies to enable delivery of effective and quality health services.

This study has revealed that a high proportion of perinatal deaths occurred in babies born with low Apgar score of $0-6$. The findings are consistent with those of previous studies in China, Croatia and Uganda that showed that babies with low Apgar score are more likely to die during the perinatal period (15-19). Our study showed that nearly a half of the cases (babies who died) were fresh still births. It's perturbing to note that nearly half of the babies who had low Apgar score who died had not been resuscitated. Apgar score assessment at 1 minute reflects the need for immediate resuscitation. The 5minute score, and particularly the change in the score between 1 and 5 minutes reflect the effectiveness of resuscitation (20). The basic step in resuscitation requires any infant should have the airway cleared of mucous, blood or meconium (20-21). If the infant is breathing, the heart rate is $>100$ beats per minutes the skin (central and mucous membrane) is pink, then routine supportive care is provided. However, if the delivery is complicated by meconium and the infant is not vigorous, endotracheal intubation is recommended (20-21). The lack of resuscitation suggests failure of the health system to meet maternal and child health needs. It suggests the need to 
improve the quality of health care services at all tiers primary, secondary and tertiary levels of the health system in the region. Our study findings suggest the need for improving staffing level and for equipping of health facilities, including both first line and referrals in the district/region. There is need to upgrade the level of knowledge and skills of available staff to effectively carry out resuscitation measures in the settings.

There were limitations to our study. The study was conducted in an urban referral hospital setting. However, the hospital serves both the urban and rural community of Arua district and other districts in the region. The majority $(>90 \%)$ of the population of the district/region though live in rural setting. Secondly, there was difficulty experienced in tracing up the mothers of controls after discharge to ascertain whether any of their babies died from home. To minimise this problem, however, mothers of controls were requested to report to the nearest maternity centre (health centre) or Arua hospital any death of a baby that occurred within one week of delivery. Mothers of controls were also given letters to take to the in - charges of the nearest maternity centre (health centre) so that any death of the control babies is immediately communicated to Arua hospital/researcher. No deaths were reported in controls.

Our study has elucidated several risk factors for perinatal deaths in the Arua regional referral hospital, West Nile region related to poor performance of the health system in the settings. The findings suggest the need for improvement of the performance of the local health systems, accessibility to and the quality of health service in the region. Firstly, there is need to improve accessibility to basic and comprehensive health services. The local district authorities and central government should endeavour to avail transport facilities ambulances for emergency referrals. Secondly, the District Health Team (DHT) and other stakeholders should strengthen the capacity of the available health facilities - first and second line. Both rural/peripheral and urban first line facilities should be adequately staffed and equipped to offer quality basic and comprehensive essential obstetric care. There is need to ensure the availability of essential equipment including for emergency obstetric care in the health facilities (rural and urban). The health personnel in the settings should receive regular refresher courses and be adequately trained in resuscitation techniques and should be regularly supervised. Strengthening the capacity of the local health system to provide effective basic and comprehensive health services remains critical to avert adverse maternal and child health outcomes in such remote resource constrained settings in the developing countries.

\section{Acknowledgements}

We are grateful to the Health Sector Strategic Plan (HSSP) Project, Ministry of Health $(\mathrm{MoH})$ for the financial support provided towards the implementation of the study. We are equally grateful for the assistance received from the District Director of Health Services, Dr Patrick Anguzu, District Health Team, Arua district, and Dr Charles Olaro the Medical Superintendent, Arua Regional Referral Hospital and all our data collectors.

\section{References}

1. Lawn JE, Cousens S, Zupan J. Lancet Neonatal Survival Steering team. 4 Million Neonatal deaths: When? Where? Why? Lancet 2005, 365:891-900.

2. World Health Organisation (WHO). Neonatal and perinatal mortality: country regional and global estimates. Geneva 2006.

3. Uganda Bureau of Statistics (UBOS) and ORC Macros .2001. Uganda Demographics and Health Survey 2000-2001.

4. Kurjak A, Asim-Bekavac I, Ivanka. Perinatal problems in developing countries: Lessons learnt and future challenges. J Perinat Med 2001, 29:17987.

5. Uganda Bureau of Statistics (UBOS). National population and housing census 2002.

6. Ministry of Finance, Planning and Economic Development (MoFPED). Challenges and prospects for poverty reduction in Northern Uganda 2002, Discussion paper 5: pp. 23-25.

7. United Nations Development Programme (UNDP). Uganda Human Development Report. The status of human development in Uganda 1996: pp: 18-30.

8. United Nations Development Prpgramme (UNDP). Uganda Human Development Report. Poverty and human development 1998. pp: 7-26.

9. Arua District Planning Office. Arua District Development Plan 2001/02 2003/04. Vol.1 Policy Framework 2002.

10. Uganda Demographic Health Survey (UDHS) 2000-2001. 2001. Key findings. ORC Calverton, Maryland. pp.10.

11. Carcillo JA, Diegel JE, Bartman BA, Guyer FR, Kramer SH. Improved maternal and child healthcare access in a rural community. $J$ Health Care Poor Underserved 1995, 1: 23-40.

12. Parkhurst JO, Penn-Kekana L, Blaauw D et al. Health systems factors influencing maternal health services: a four-country comparison. Health Policy 2005, 73:127-138.

13. Orach GC, De Brouwere V. Integrating refugee and host health services in West Nile districts, Uganda. Health Policy and Planning 2006, 21:53-64.

14. Orach GC, De Brouwere V. Costs and coverage of reproductive health interventions in three rural refugee-affected districts, Uganda. Tropical Medicine and International Health 2007, 12:459-469.

15. Airede KI. Should we resuscitate? Ethical dilemmas. Ann Trop Paediatr 1999, 11:169-74.

16. Miletic $T$, Aberle N, Mikulandra $F$ et al. Perinatal outcome of pregnancies in women aged 40 years and over. Coll Antropol 2002, 26: 251-8.

17. Ondoa-Onama C, Tumwine JK. Immediate outcome of babies with low Apgar score in Mulago Hospital, Uganda. East Afr Med J 2003, 80:22-9.

18. Chong DS, Karlberg J. Refining the Apgar Score cut-off point for newborns at risk. Acta Paediatr 2004, 93:53-9.

19. Barton $L$ and Hodgman JE. The contribution of withholding or withdrawing care to new born babies. Pediatrics 2005, 116:1487-91.

20. Cunningham L, Bloom H, Gilstrop W. Williams Obstetrics. $22^{\text {nd }}$ Edition. The Newborn Infant: Management of delivery pp. 634-637.

21. Campbell $S$ and Lees $C$. Obstetrics by ten teachers. Neonatalogy: the challenge of neonatology, organisation of delivery of neonatal care, care of normal term newborn 2000:pp. 331-343. 